\title{
Immunopathology in ocular toxoplasmosis: facts and clues
}

\author{
Justus G Garweg1/+ ${ }^{+}$Ermanno Candolfi \\ ${ }^{1}$ Clinic for Vitreoretinal Disease and Uveitis, Swiss Eye Institute, Bremgartenstrasse 119, CH - 3012 Bern, Switzerland ${ }^{2}$ Institut de Parasito- \\ logie et de Pathologie Tropicale, EA 3950 Interactions Cellulaires et Moléculaires Hôte-Parasite, Université Louis Pasteur de Strasbourg, \\ Strasbourg, France
}

\begin{abstract}
Although parasite-mediated host cell lysis is deemed to be an important cause of tissue destruction in ocular toxoplasmosis (OT), the severity of the disease is probably correlated with hypersensitivity and inflammation. Notwithstanding, the mechanisms that regulate the inflammatory process in recurrent OT are poorly understood. Recent evidence has identified interleukin (IL) 17 as a marker for disease severity. The ocular and cerebral presence of this cytokine is generally associated with the induction of autoimmune responses in the brain and the eye. Indeed, there are indications that autoimmunity may contribute to clinical variability in the activity of OT. IL-23, which induces the proliferation of IL-17-producing cells and IL-27, which is a counterplayer to IL-17, may regulate $T(H)$-1-cell-mediated responses in OT. The importance of these cytokines in experimental models of uveitis and encephalitis has been recently reported. CD25(+) regulatory T-cells may control the local inflammatory response and protect the host against collateral inflammatory tissue damage. The responses of these cells to OT may be suitably tailored to cope with either an acquired or a congenital aetiology. Knowledge relating to immunoreactivity in OT has grown impressively during the past few years. Its characteristic and variable features have been identified and the potential relevance of autoimmunity has been assessed. In light of this knowledge, potential future treatment options have been considered.
\end{abstract}

Key words: ocular toxoplasmosis - acquired toxoplasmosis - congenitally contracted toxoplasmosis experimental autoimmune uveitis - cytokines - chemokines

The term uveitis embraces a complex group of diseases that are instigated by local tissue trauma. The insult may be triggered by various agents, including infectious organisms. Autoimmunity may be a late consequence of microbe-induced injury. Recurrences can be triggered either by the reappearance of the infectious agent within the target tissue or by an accumulation of immune complexes within the uveal tract. Immunoregulation can be influenced by pregnancy, aging and emotional disturbances (O'Connor 1983).

Ocular toxoplasmosis (OT) or, more precisely, toxoplasmic retinochoroiditis is the most frequent cause of infectious blindness and visual morbidity amongst young adults in developed countries. The severity of the disease varies greatly between patients. OT is characterized by necrotizing retinopathy, which is triggered by the activation of dormant organisms within the retina. Although the contribution of anti-retinal autoimmune mechanisms to the destruction of retinal tissue has been a subject of debate for many years (Cogan 1977), the pathogenesis of the inflammatory process in OT remains obscure (Roberts \& McLeod 1999, Yap \& Sher 1999, Gaddi \& Yap 2007).

Financial support: The authors have disclosed any financial proprietary interests and did not receive any funding from third parties in the context of the data presented herein.

+ Corresponding author: justus.garweg@swiss-eye-institute.com

Received 16 October 2008

Accepted 2 February 2009
In accordance with the clinical presentation in humans, a histopathological study of congenital OT in mice has revealed great variability in the degree of tissue destruction. Toxoplasma-containing cysts are found within the retina and the optic nerve irrespective of the disease severity, although they are rarely observed in mildly affected eyes. In the latter cases, the hallmarks of the disease are low-grade uveitis and retinal lymphocytic perivasculitis. In more severely affected eyes, retinal destruction may be focal, sectorial or total, and it is usually associated with secondary cataract formation. In some eyes, inflammatory destruction of the outer retina is associated either with a death of cells or with the infiltration of lymphocytes or plasma cells; granulomatous reactions are rare. In the most severely affected eyes, the retina can be completely necrotic and calcified (Lee et al. 1983). Cataracts and selective destruction of the photoreceptor layer may occur specifically in congenitally infected mice (Hay et al. 1981, Hutchison et al. 1982).

\section{Organ-specific aspects of ocular inflammation}

The eye is generally considered to be an immunologically privileged organ owing to the existence of a tight blood-vascular barrier, the lack of lymphatic drainage, and the paucity of classical antigen-presenting cells. However, this dogma is now open to challenge, since there are indications for an active communication between the immune system and the eye and for the ocular presentation of exogenous as well as endogenous antigens. According to current knowledge, cell-mediated and non-inflammatory humoral immune responses within the eye are regulated by cytokine-mediated, ac- 
tive immunosuppressive mechanisms. These mechanisms include the apoptosis of alloreactive lymphocytes and aim to curb the tissue-destructive effects of the inflammatory reactions, both locally and within the brain (Esterre 1996, Caspi 2006).

The retina is a complex structure, both architecturally and antigenically. Since it develops as an extension of the neural tube, it shares several membranous and cytoplasmic antigens in common with the brain, including those of the neuro and glial filaments. Several antigens that are specific to the nervous system are abundant within the retina. Antigens that are specific to the eye include those of the retinal pigmented epithelium, retinal ganglion cells and astrocytes. The outer segments of the photoreceptor cells contain soluble antigens which, when injected into rats, rabbits, guinea pigs or monkeys, evoke varying degrees of intraocular inflammation that can lead to uveitis, retinal detachment, degeneration of the photoreceptor cells and, occasionally, retinal vasculitis. Both cell-mediated and humoral immunity to photoreceptor antigens have been demonstrated in various types of uveitis (including OT and sarcoidosis). Retinal autoimmunity can occur in conjunction with retinal detachment and diabetic retinopathy, particularly after photocoagulation with argon-laser light. In patients with systemic immune disorders, such as lupus erythematosus, antibodies against retinal antigens have been detected even when the eye is not involved. Hence, the precise pathogenic role of retinal autoimmunity in ocular diseases is not known with certainty. It may represent no more than an epiphenomenon that develops after physically, immunologically, or microorganism-induced retinal damage. Alternatively, autoimmunity while itself failing to evoke ocular inflammation may, by perpetuating and sustaining the level of a pre-existing inflammatory state, elicit further damage within ocular tissues (Rahi \& Addison 1983). Support for this contention has been provided by Muiño et al. (1999). These authors reported five to 10 -fold higher levels of IgE and 2-3-fold higher levels of sCD23 in patients with either autoimmune uveitis or OT than in healthy controls. Immunoglobulins specific to the retinal S-antigen were detected in more than $80 \%$ of the cases and those of the IgE class accounted for nearly $70 \%$ of these immunoglobulins. Specific IgE was found in two-thirds of the patients with autoimmune uveitis, but it was not detected in either the controls or in individuals with bacterial uveitis. Elevated levels of total IgE and sCD23 and the presence of antibodies against $\mathrm{S}$-antigen are indicative of $\mathrm{T}$ (helper) 2[T(H)-2] cell activation (Muiño et al. 1999).

With the aid of indirect immunofluorescence, Whittle et al. (1998) detected a strong signal within the photoreceptor layer of more than $90 \%$ of their OT patients. A lower level of reactivity (40\%) was observed within the photoreceptor layer of the healthy subjects and of individuals with retinal vasculitis. Antibodies against the retinal S-antigen were detected in $75 \%$ of the patients who were suffering from either OT or retinal vasculitis. However, they were also present in more than $60 \%$ of the controls. Hence, anti-retinal reactivity in OT patients cannot be accounted for by the presence of anti-S-antigen alone. The prevalence of anti-photoreceptor antibodies indicates that they occur naturally. Their elevated levels in more than $90 \%$ of the patients suffering from OT suggest that, in this disease, they may be co-pathogenic (Whittle et al. 1998). More recently, mononuclear cells derived from the peripheral blood of patients who were suffering from mild OT were found to respond to one or more retinal antigens with a significantly higher frequency than those that were obtained from either healthy subjects or individuals with severe OT. Cytokine production by the proliferating mononuclear cells did not follow a specific pattern. The only consistent trend was the rare occurrence of IL-4 and IL-5. These findings indicate that an autoimmune response may assist in controlling inflammation, thereby helping to curb the severity of the disease (Vallochi et al. 2005).

\section{Immunoregulation of inflammatory activity}

Although parasite-mediated host cell lysis is probably the principal cause of tissue destruction in immunodeficiency states, hypersensitivity and inflammation exacerbate the process in otherwise immunocompetent individuals (Gaddi \& Yap 2007).

There are indications that autoimmunity may contribute to clinical variability in disease activity (Luger \& Caspi 2008). In a murine model of toxoplasmic encephalitis, Stumhofer et al. (2006) demonstrated that local autoimmune activity is driven by the development of IL-17-producing $\mathrm{T}(\mathrm{H})$ cells, but is counterbalanced by the production of cytokines that antagonize the effector responses of these cells. IL-27 receptor-deficient mice that have been chronically infected with Toxoplasma gondii develop a severe form of neuroinflammation that is $\mathrm{CD} 4(+)$ T-cell-dependent and associated with a prominent IL-17 response. Treatment of naïve primary T-cells with IL-27 in vitro suppressed the development of $\mathrm{T}(\mathrm{H})-17$ cells that had been induced via the application of IL- 6 and transforming growth factor- $\beta$ (TGF- $\beta$ ). Since IL-27 appears to counterbalance the development of $\mathrm{T}(\mathrm{H})-17$ cells, the latter could serve as a useful treatment target for inflammatory responses that result from Toxoplasma-induced activation of CD4(+)T-cells (Stumhofer et al. 2006).

\section{IL-17: a key player in the regulation of inflammatory activity}

Activated T-cells follow distinct developmental pathways that endow them with specialized properties and effector functions. $\mathrm{T}(\mathrm{H})$-cells are traditionally believed to differentiate into $\mathrm{T}(\mathrm{H})-1$ - and $\mathrm{T}(\mathrm{H})-2$-subsets subsets, the former being necessary for the clearance of intracellular pathogens and the latter that of extracellular organisms. A distinct subset of IL-17-producing T(H)-17 cells has recently been described and these cells have been shown to play a crucial role in the induction of autoimmune tissue injury (Afzali et al. 2007, Romagnani 2008). The evolution of these IL-17-producing $\mathrm{CD}(4+)$ T-cells from naïve precursors during an immune response is independent of the cytokines and transcription factors that mediate the development of $\mathrm{T}(\mathrm{H})-1$ and $\mathrm{T}(\mathrm{H}) 2$ lineages. CD4(+), CD25(+) and Foxp3(+) regulatory (reg) T-cells, on the other hand, inhibit autoimmunity and protect the host against 
tissue injury. TGF- $\beta$ is crucial for the generation of these $\mathrm{T}(\mathrm{reg})$-cells. Evidence is rapidly accumulating that rheumatoid arthritis and multiple sclerosis are primarily IL17-mediated autoimmune inflammatory diseases.

In several animal models of autoimmunity, IL-17 has been shown to play a crucial regulatory role in tissue inflammation and disease development. Consequently, IL-17-producing CD4(+) T-cells have been deemed to represent a distinct inflammatory $\mathrm{T}(\mathrm{H})$-cell lineage characterized by the production of IL-17, IL-6, IL-22 and TNF- $\alpha$ (Dong 2006).

IL-17 and IL-22 can induce the disruption of the endothelial tight junctions that comprise the blood-brain barrier and, in consequence, $\mathrm{T}(\mathrm{H})$-17-lymphocytes can cross the vascular endothelium. These cells also express high levels of granzyme B, can destroy human neurones and can promote inflammation of the central nervous system via recruitment of CD4(+) lymphocytes (Kebir et al. 2007). Moreover, the blood-brain barrier itself can promote the differentiation of migrating CD14(+) monocytes into $\mathrm{T}(\mathrm{H})$-17-polarized CD83(+) CD209(+) dentritic cells under the influence of TGF- $\beta$ and GMCSF (Ifergan et al. 2008).

The development of $\mathrm{T}(\mathrm{H})-17$ cells from naïve precursors can be inhibited by interferon (IFN)- $\gamma$ and IL-4, whereas committed $\mathrm{T}(\mathrm{H})-17$ cells are resistant to suppression by $\mathrm{T}(\mathrm{H})-1-$ or $\mathrm{T}(\mathrm{H})$-2-cell cytokines. In the absence of IFN- $\gamma$ and IL-4, IL-23 derived from dendritic cells can induce the differentiation of naïve precursor cells into $\mathrm{T}(\mathrm{H})-17$ cells independently of the transcription factors STAT1, T-bet, STAT4 and STAT6. This circumstance could account for the finding that inhibition of IFN- $\gamma$ signalling enhances the development of pathogenic $\mathrm{T}(\mathrm{H})-17$ effector cells that can exacerbate autoimmunity (Harrington et al. 2005).

In a murine model of experimental autoimmune encephalomyelitis, IL-17 has been shown to induce the expression of chemokines within the brain. Moreover, over-expression of IL-17 within the pulmonary epithelium evokes the production of chemokines and the infiltration of leukocytes. IL-4 and IFN- $\gamma$ negatively regulate the production of IL-17 (Park et al. 2005).

Endogenous and exogenous IL-1 dramatically influences the TGF- $\beta$ and IL-6-induced differentiation of IL17 T-cells. Indeed, IL-1 is capable of stimulating the differentiation of IL-17 T-cells, even in the absence of IL-6. Furthermore, although IL-2 suppresses the differentiation of IL-17 T-cells, this effect can be overcome by the effect of IL-1. IL-6 is important for the differentiation of IL-17 T-cells, but it is not indispensable, whereas IL-1 is mandatory. These findings indicate that the size of the IL-17 T-cell pool can be controlled by the local cytokine profile (Kryczek et al. 2007).

$\mathrm{T}(\mathrm{H})-17$ cells are known to be involved in several ocular diseases, including uveitis and scleritis. Expansion of the $\mathrm{T}(\mathrm{H})-17$-cell pool is promoted by IL-2 and inhibited by IFN- $\gamma$. The numerical density of these cells correlates with the level of activity of the uveitic and scleritic disease. In experimental autoimmune uveitis, elevated levels of IL-17 evoke an up-regulation of tumour necrosis factor- $\alpha(\mathrm{TNF}-\alpha)$ in retinal cells, by which $\mathrm{T}(\mathrm{H})-17$ cells may contribute to inflammatory tissue damage. On the other hand, IL-27, which is constitutively expressed in retinal ganglion and photoreceptor cells in response to IFN- $\gamma$, inhibits the proliferation of T(H)-17 cells. Hence, IFN- $\gamma$-producing $\mathrm{T}(\mathrm{H})-1$ cells could mitigate uveitis by antagonizing the $\mathrm{T}(\mathrm{H})-17$ phenotype, namely, by IFN$\gamma$-mediated induction of IL-27 within the target tissue. The ability of IL-2 to promote the expansion of T(H)-17 cells is known based on the efficacy of the IL-2 receptor antibody in treating uveitis. IFN- $\gamma$ or IL-27-mediated antagonism of $\mathrm{T}(\mathrm{H})-17$ cells could serve as alternative therapeutic options in the treatment of chronic intraocular inflammation (Amadi-Obi et al. 2007).

\section{Cytokines in the regulation of immunity and in in- duction of autoimmunity}

The differentiation of $\mathrm{T}(\mathrm{H})-17$ cells from naïve precursors is induced by IL- 6 and TGF- $\beta$. TGF- $\beta$ alone can induce the expression of Foxp 3 and the expansion and differentiation of $\mathrm{T}(\mathrm{reg})$ cells, which protect the host against autoimmunity (Bettelli et al. 2006). IL-6 inhibits the TGF- $\beta$-driven expression of Foxp3, thereby facilitating the formation of $\mathrm{T}(\mathrm{H})-17$ cells, which promote inflammation and autoimmunity. Thus, IL-23 can induce the expansion of fully differentiated $\mathrm{T}(\mathrm{H})-17$ cells (Bettelli et al. 2007).

Only two years ago (Mucida et al. 2007), retinoic acid was identified as a key regulator of TGF- $\beta$-dependent immune responses. It was found to be capable of inhibiting the IL-6-driven induction of proinflammatory $\mathrm{T}(\mathrm{H})$ 17 cells and of promoting the differentiation of anti-inflammatory $\mathrm{T}$ (reg) cells. This recent discovery exposes our still limited understanding of the factors that play a role in the counterbalance between pro and anti-inflammatory activity (Mucida et al. 2007).

Although the transcription factor T-bet is crucial for the differentiation of IFN- $\gamma$-producing CD4(+) T(H)-1 lymphocytes, its role in the differentiation of $\mathrm{T}(\mathrm{H})-17$ cells is poorly understood. Therapeutic administration of a small interfering (si)RNA specific to T-bet significantly improves the clinical course of experimental autoimmune encephalomyelitis. This T-bet-specific siRNA suppresses the differentiation of IL-17-expressing T-cells in the central nervous system, as well as that of myelin-basic-protein-specific autoreactive $\mathrm{T}(\mathrm{H})-1$ cells. Moreover, T-bet directly regulates the transcription of the IL-23 receptor and, as a consequence, indirectly influences the number of $\mathrm{T}(\mathrm{H})-17$ cells, which depend on IL-23 for their survival. Correspondingly, suppression of T-bet ameliorates experimental autoimmune encephalomyelitis by limiting the differentiation of autoreactive $\mathrm{T}(\mathrm{H})-1$ cells, as well as via IL-23 receptor-mediated inhibition of pathogenic T(H)-17 cells (Gocke et al. 2007).

\section{The counteraction between IL-17 and IL-27}

IL-12 has been long known to play a central role in the generation of $\mathrm{T}(\mathrm{H})-1$ cells and more recent evidence has implicated two related cytokines, IL-23 and IL-27, in the regulation of $\mathrm{T}(\mathrm{H})-1$-cell responses. IL-23 appears to be capable of stimulating a unique subset of T-cells to produce IL-17, which plays a prominent role in autoim- 
mune inflammation. IL-27, on the other hand, can dampen the intensity and curtail the duration of adaptive immune responses (Hunter 2005). IL-27 is distinguished from other members of the IL-12 cytokine family by its specific effect on naïve CD4(+) T-cells in both humans and mice (Cordoba-Rodriguez \& Frucht 2003). It is a potent inhibitor of the development of $\mathrm{T}(\mathrm{H})$-17-cells. Not surprisingly, therefore, subcutaneous administration of IL-27 in mice dramatically suppresses active experimental autoimmune encephalomyelitis: inflammatory infiltration into the central nervous system is reduced and the numerical density of $\mathrm{T}(\mathrm{H})-17$ cells decreases (Fitzgerald et al. 2007, Furuzawa-Carballeda et al. 2007, Wang et al. 2008).

By suppressing TGF- $\beta$-induced expression of the transcription factor Foxp3, IL-27 also inhibits the development of anti-inflammatory, inducible regulatory (ireg) T-cells. While the blockage of $\mathrm{T}(\mathrm{H})-17$-cell development depends on the transcription factor STAT1, suppression of T(ireg)-cell development does not, which suggests that IL27 utilizes a different signalling pathway to shape T-celldriven immune responses. Hence, IL-27 can differentially control the development of $\mathrm{T}(\mathrm{H})-17$ and $\mathrm{T}(\mathrm{ireg})$ cells via its differential effects on STAT1 (Neufert et al. 2007).

Mice that lack the receptor for IL-27 manifest exaggerated inflammatory responses to a variety of challenges. This finding indicates that IL-27 possesses an important immunoregulatory function in vivo. IL-27 receptor-deficient mice are highly susceptible to experimental autoimmune encephalomyelitis, to which they respond by generating an abundance of $\mathrm{T}(\mathrm{H})-17$ cells. IL-27 thus appears to act directly on effector Tcells to suppress the IL- 6 and TGF- $\beta$-induced differentiation of the $\mathrm{T}(\mathrm{H})-17$ lineage. This effect is linked to the transcription factor STAT1 and is independent of IFN- $\gamma$. Moreover, IL-27 has been shown to suppress the IL-6-mediated proliferation of T-cells. This effect may account for the IL-27-mediated suppression of immunoreactivity that has been observed in several in vivo models of inflammation (Batten et al. 2006). For example, infection of IL-27 receptor-deficient mice with $T$. gondii elicits aberrant IL-2 responses, which are associated with the development of a lethal inflammatory disease. Since in vivo depletion of IL-2 prolongs the survival of Toxoplasma-infected IL-27 receptor-deficient mice, IL27 probably controls the development of immunopathology by limiting the parasite-induced production of IL-2. Consistent with this hypothesis, the CD4(+) T-cells of IL-27 receptor-deficient mice produce higher levels of IL-2 than those obtained from wild-type counterparts during their differentiation in vitro. Introduction of recombinant IL-27 suppresses the expression of the IL-2 gene and protein in the former cells. IL-12 (unlike IL-16 and IL-23) also inhibits the production of IL-2, thus enhancing the immunoregulatory effect. IL-27 and IL-12 thus appear to co-operate in limiting the availability of IL-2 and thus in controlling the growth and survival of T-cells (Villarino et al. 2006).

Finally, IL-10 contributes to the balance between protective and pathological T-cell responses and is re- quired for host survival. It is produced by many different cell types, including myeloid cells, several T-cell subsets and antigen-presenting dendritic cells. The production of IL-10 by T-cells can be induced by IL- 6 and IL- 27 via a STAT3-mediated pathway, and TGF $\beta$ - and IL-6-induced $\mathrm{T}(\mathrm{H})-1$ and $\mathrm{T}(\mathrm{H}) 2$-cells, as well as $\mathrm{T}(\mathrm{H})-17$ cells, contribute to its secretion (Awasthi et al. 2007). The production of IL-10 is important for an effective immune response to T. gondii and T-bet $(+) / F o x p 3-\mathrm{T}(\mathrm{H})-1$ are its major source (Jankovic et al. 2007, Stumhofer et al. 2007). Recent evidence indicates that FoxP3-expressing CD4(+)/CD25(+) $\mathrm{T}$-cells might be actively involved in the development of tolerance to TGF- $\beta$ (2)-induced antigen-presenting cells (Matsumura et al. 2007, Zhang et al. 2008), which could contribute to the recurrence of OT.

\section{IL-23 and the therapeutic consequences of its targeting}

The role of IL-12 in modulating cellular immune responses has been hitherto overestimated owing to the previous belief that the $\mathrm{p} 40$ subunit is unique to this cytokine. However, this subunit is now known to be shared by IL-12 and IL-23. p40(-/-) mice are deficient in both IL12 and IL-23. Indeed, studies with these knockout mice have revealed that the essential role previously attributed to IL-12 in experimental autoimmune encephalitis must now be conferred to IL 23 (Cordoba-Rodriguez \& Frucht 2003). IL-23 drives the development of a highly pathogenic T-cell population that is involved in the induction of autoimmune diseases. This cytokine is implicated in the differentiation of autoreactive IL-17-producing Tcells and promotes chronic inflammation. This process is dominated by IL-17, IL-6, IL-8 and TNF- $\alpha$ (not IFN- $\gamma$ and IL-4), as well as by neutrophils and monocytes. IL23 is a key player in numerous autoimmune diseases, such as experimental allergic encephalomyelitis, collagen-induced arthritis and inflammatory bowel disease. The downstream effects of IL-23 are believed to have evolved with the sole purpose of causing autoimmunity. The evolutionary advantages of these effects are not understood, but they lie in the regulation of IL-17-producing $\mathrm{T}(\mathrm{H})-1$ cells (McKenzie et al. 2006). Blocking IL-23 or its downstream factors IL-17 and IL-6 can significantly suppress the development of inflammatory bowel disease and multiple sclerosis in animal models. Inhibition of the IL-12/IFN- $\gamma$ pathway has no such effect. The IL-23/IL-17 pathway could thus serve as a novel therapeutic target for the treatment of chronic inflammatory diseases (Iwakura \& Ishigame 2006).

Although the transcription factors T-bet and STAT1 are not required for the initial production of IL-17, the former appears to be necessary to optimize the IL-23stimulated process. Treatment with anti-IL-23p19 lowers the serum level of IL-17, as well as the gene expression levels of IFN- $\gamma$, IP-10, IL-17, IL- 6 and TNF- $\alpha$ in the central nervous system. Furthermore, anti-IL-23 therapy of animals during an active stage of experimental autoimmune encephalomyelitis averts subsequent relapse. The therapeutic targeting of IL-23 can thus effectively inhibit multiple pathways that underlie inflammation of the central nervous system in experimental autoimmune encephalomyelitis (Chen et al. 2006). 


\section{Cytokines and T-cell regulation in toxoplasmic en- cephalitis}

Infection with $T$. gondii is an important cause of diseases of the central nervous system and the eye in immunocompromised as well as immunocompetent individuals. Although the parasite-mediated lysis of host cells is probably the principal cause of tissue destruction in states of immunodeficiency, hypersensitivity and inflammatory responses probably contribute to this process in otherwise immuno-sufficient individuals. Experimental evidence implicates CD4(+) T-cells in the systemic and local immunopathological responses that are associated with toxoplasmic infection. The pathogenic roles of the cytokines produced by $\mathrm{T}(\mathrm{H})-1$ and $\mathrm{T}(\mathrm{H})-17$ cells and the protective and homeostatic roles of IL-10, TGF- $\beta$ and IL-27 in modulating the hypersensitivity responses induced by $T$. gondii are now generally recognized (Gaddi \& Yap 2007).

Toxoplasma-infected macrophages induce the production of IFN- $\gamma$, IL-2, IL-4 and IL-10 by CD4(+) T-cells and that of IFN- $\gamma$ and IL- 2 by CD8(+) T-cells. The production of IL- 4 and IL-10 by CD4(+) T-cells can suppress the IFN- $\gamma$-mediated mechanisms that protect the host against the parasite (Miller et al. 2006).

Microglia and macrophages within the brains of healthy individuals produce IL-10 at the gene-expression and protein levels. In individuals with toxoplasmic encephalitis, CD4(+)- and CD8(+) T-cells likewise produce IL-10. In patients who are suffering from chronic toxoplasmic encephalitis, neutralisation of endogenous IL-10 leads to a reduction in the intracerebral parasitic load, an increase in the numerical density of immune cells and an up-regulation in the production of protective cytokines. Hence, the intracerebral expression of IL-10 interferes with the immune response in toxoplasmic encephalitis and may contribute to the persistence of parasites within the brain (Deckert-Schlüter et al. 1997).

Although IL-17 is not necessary for the development of adaptive immunity to $T$. gondii, its absence impedes the early migration of neurophils to the sites of infection, which can have fatal consequences for the host (Kelly et al. 2005). The up-regulation of IL-4 in a Toxoplasmainfected host indicates the host is susceptible to the parasite, even if it is previously deemed to be resistant to the organism (Welter et al. 2007).

Production of IFN- $\gamma$ by T-cells, natural killer cells and various other cell types in the brain protects the host against toxoplasmic encephalitis. In animal models, microglia produce IFN- $\gamma$ in response to infection with $T$. gondii (acute or reactivated), irrespective of whether T-cells are absent or present. Since IFN- $\gamma$ can induce expression of the chemokines and MHC-antigens necessary for the recruitment and activation of T-cells, its production by microglia during the early stages of tachyzoite proliferation in the brain may be crucial in limiting parasitic growth and in the later development of T-cell immunity (Wang \& Suzuki. 2007). Pretreatment of microglia with recombinant TNF- $\alpha$ and prolactin has a toxoplasmastatic effect: the parasites are destroyed intracellularly and IL-1 $\beta$, IL-3, and IL-6 are released. The intercellular adhesion molecule 1 (ICAM-1) is also upregulated and may be involved in the recruitment of leukocytes (Benedetto et al. 2001).

In a murine model of toxoplasmic encephalitis, inactivation of the vascular cell adhesion molecule 1 (VCAM)-1 or of the VCAM-1 gene appears to abolish the host's resistance to the parasite. Although the recruitment of leukocytes is unimpaired, the B-cell response is significantly dampened, as evidenced by the reduced serum levels of specific IgM and IgG. VCAM-1-mediated immune reactions are thus necessary to control intracerebral infection with $T$. gondii (Deckert et al. 2003).

\section{Autoimmunity in OT}

In human patients, OT may be partially mediated by an autoimmune mechanism, which might reflect the presence of immunodominant membrane antigens with a high affinity for the retina (Nussenblatt et al. 1989).

Autoimmune reactions against retinal antigens are believed by some investigators to play an important role in human uveitis. However, the evidence in support of this belief is equivocal. Humoral and cellular autoreactivity against retinal antigens has been detected not only in uveitic patients, but also in healthy controls (Kijlstra et al. 1990). In a study conducted nearly 30 years ago, lymphocytes derived from patients with active or inactive $\mathrm{OT}$, as well as from sero-positive and sero-negative controls, were exposed to human retinal antigens in vitro. A proliferative response was observed for many of the patients with active OT, for half of those with inactive OT and for none of the healthy controls who registered either sero-positive or sero-negative (Wyler et al. 1980).

These data afforded some evidence for an autoimmune component in the pathogenesis of OT, but this contention has yet to be unequivocally confirmed.

Mice that have been infected in utero with $T$. gondii demonstrate histopathological features of OT ranging from minimal damage to complete destruction of the retinal tissue. Retinal vasculitis and highly selective destruction of the photoreceptor cells were consistent findings and these features are also characteristic of experimental autoimmune retinitis (Lee et al. 1983, Hay et al. 1984).

As previously mentioned, serum antibodies against retinal antigens have been detected in healthy individuals. Such "natural" autoantibodies may act in a protective capacity, as indeed they generally do in autoimmune diseases (Forrester et al. 1989). Nevertheless, the incidence of antibodies against the S-antigen - a major glycoprotein in photoreceptor cells - is 2-fold higher in uveitic patients than in healthy controls and the levels rise during active stages of the disease. Anti-S antibodies could thus arise from non-specific inflammatory damage to the retina and uvea. Whether such a secondary autoimmune response could perpetuate the disease is open to question, but is doubtful since patients who have undergone repeated surgery for unsuccessful retinal reattachment surgery display serum levels of the anti-S antibody that do not correspond with the clinical grading of intraocular inflammation (García et al. 1988). Furthermore, in a rodent model of OT, intraocular injection of the S-antigen failed to evoke uveitis (Pereira Mde et al. 1999). 
In contrast to the $\mathrm{S}$-antigen, the interphotoreceptor retinoid binding protein (IRBP) can induce experimental autoimmune uveitis in susceptible animal strains. However, serum antibodies against human IRBP have been detected with equal frequencies in both uveitic patients and healthy controls and without apparent differences in the antibody levels or avidities (Hoekzema et al. 1990).

The pathogenesis of experimental autoimmune uveitis, experimental OT, and most instances of human posterior uveitis involves the cell-mediated destruction of retinal tissues. Since T-cells with retinal antigen specificity are required for this process, the presence of antiretinal antibodies in humans may reflect a potential to develop autoimmunity. But these anti-retinal antibodies need not actively mediate inflammation (Klass et al. 1991, Lu et al. 2004).

Moreover, at least in recurrences of OT, the immune response is a highly localized and compartmentalized event, which is confined to B-cell activity and thus to lymphocyte homing (Klaren \& Peek 2001). Only an analysis of the specificity of the T-cell infiltrate or of the immunoglobulins that are deposited within the diseased tissues can furnish conclusive evidence of an autoimmune component (Kijlstra et al. 1990). Toxoplasmic, but not retinal antigens, have been detected in lymphocytes derived from the vitreous of patients with active OT. Most of the intraocular antigen-specific T-cells were found to be of the $T(H)-0 / T(H)-2$ linage (Feron et al. 2001). Ocular inflammatory response to T. gondii is mediated primarily by CD4(+) T-cells, but CD8(+) T-cells and B-cells may be involved in curbing local parasitic growth (Lu et al. 2004).

\section{Immunogenetics}

The role of immunogenetics in the pathogenesis of OT is poorly understood. The genetic makeup of the host as well as the strain-specific virulence of the parasite is known to influence the susceptibility of mice to experimental OT (Lu et al. 2005).

To assess the influence of host genetic background on the differentiation of $\mathrm{T}(\mathrm{H})$-cells, a comparative study employing $\mathrm{T}(\mathrm{H})-2$-prone $\mathrm{BALB} / \mathrm{c}$ and $\mathrm{T}(\mathrm{H})-1$-prone $\mathrm{C} 57 \mathrm{BL} / 6$ mice was undertaken. IL-4, the production of which is induced by IL-2, is expressed at higher levels in BALB/c-naïve CD4(+) T-cells than in C57BL/6-naïve CD4(+) T-cells. Consequently, the former are more prone than the latter to differentiate into cells of the $\mathrm{T}(\mathrm{H})-2$ lineage. STAT5 is preferentially activated in $\mathrm{BALB} / \mathrm{c}$-naïve $\mathrm{CD} 4(+) \mathrm{T}-$ cells, initially in response to IL-2 and then IL-4. STAT6 is activated to the same degree in both cell types (Yagi et al. 2006). Furthermore, when $\mathrm{T}(\mathrm{H})$-2-prone BALB/C mice are intraocularly infected with $T$. gondii, parasitic growth is arrested; but when $\mathrm{T}(\mathrm{H})-1$-prone $\mathrm{C} 57 \mathrm{BL} / 6$ mice are inoculated with the same parasitic strain, the organism continues to proliferate within the eye. In the latter mouse strain, the immune response is regulated by IFN- $\gamma$ rather than by IL-4 (Norose et al. 2003).

The data gleaned from studies with animal models of OT may be species-specific and thus not relevant in a human context. For example, class-I MHC is up-regulated in murine models of OT (Lyons et al. 2001), whereas this may not be the case in rats (Sergent et al. 2005). In patients suffering from OT, the expression of the human counterpart, the HLA antigens, is not significantly higher than in healthy controls (Ohno et al. 1977, Nussenblatt et al. 1989). However, human genotypes characterized by low production of IL-10 may be more prone to the development of human OT (Cordeiro et al. 2008).

\section{Chemokines}

Patients with toxoplasmic retinochoroiditis, especially those with vasculitis, manifest 2.5 -fold higher serum levels of the chemokine CXCL8 than healthy controls. The levels of other chemokines do not differ between the two groups of individuals. There is evidence that the serum levels of both CXCL8 and CXCL9 correlate with the size and activity of the ocular lesions (Gonçalves et al. 2007). These chemokines may be partially derived from Mueller cells. Infection of these cells with T. gondii in vitro elicits the expression of high levels of CXCL2 and CXCL8, which could promote the recruitment of polymorphonuclear cells, as well as the production of GRO1, MCP-1, FKN and RANTES by retinal vascular endothelial cells (Knight et al. 2005, 2006).

The role of Fas and its ligand (FasL) in OT has yet to be clarified. In one study utilising mice, intraocular infection with $T$. gondii elicited local inflammation, which was associated with a local increase in the expression of Fas and FasL. Inflammatory and ocular tissue cells underwent apoptosis and the numerical density of $\mathrm{CD} 8(+)$ cells increased more than that of CD4(+) T-cells in the infected eyes. Fas/FasL-driven apoptosis was presumed by the authors to be involved in the pathogenesis of acquired OT (Hu et al. 1999), but in a later study involving mutant mice that lacked the genes for either Fas or FasL, the levels of ocular inflammation and apoptosis were similar in these animals compared to their wildtype counterparts after intraocular challenge with $T$. gondii. However, after challenging the mutant mice with T. gondii, the expression of IFN- $\gamma$ in the brain and in the eyes was up-regulated earlier and the levels of nitrite in the ocular tissues were higher than those observed in wild-type animals (Shen et al. 2001). Fas/FasL- driven apoptosis may thus be neither related to the IFN- $\gamma$ response nor be involved to a significant degree in the immunoregulation of OT. In a further study, this time with C57BL/6 mice, the levels of MIP-2, Fas and FasL- in the serum were reported to be similar in non-infected and Toxoplasma-infected animals, whereas their levels in the aqueous humour were higher in the latter than in the former (Calabrese et al. 2008).

In human uveitis, the levels of Fas and FasL in the intraocular fluid have been found to correlate positively with the activity of the disease. However, these chemokines were not detected in the serum. Soluble FasL has also been detected in the aqueous humour of non-uveitic eyes with age-related cataracts (Sugita et al. 2000). In organisms that are resistant to Fas-FasL, Fas-FasL and TRAIL are involved in tumour surveillance of the eye and may also contribute to the development of immune privilege in cases of infectious uveitis. In patents with OT, as opposed to those who are systemically infected 
(Mordue et al. 2001), FasL- or TRAIL-mediated apoptosis of immune cells within the eye may protect it from the damaging effects of infiltrating inflammatory cells and thus help to preserve vision (Lee et al. 2002).

\section{Cytokines in OT}

Knowledge of the pattern of cytokine production in various forms of uveitis could be of therapeutic value. The two groups of cytokines, T1 (IFN- $\gamma$, IL-2, IL-12) and T2 (IL-4, IL6, IL-10) represent two polar responses of the immune system. The T1-group of cytokines is involved predominantly in cellular responses, whereas the T2-group is implicated primarily in humoral ones.

In OT, the pathogenic roles of the cytokines produced by $\mathrm{T}(\mathrm{H})-1$ and $\mathrm{T}(\mathrm{H})-17$ cells, and the protective and homeostatic roles of IL-10, IL-27 and TGF- $\beta$ in modulating the host's hypersensitivity response to T. gondii have been only partially elucidated (Gaddi \& Yap 2007).

In chronically infected individuals, this response appears to be strictly activation site-specific, since, with respect to activation markers and the production of T1-group cytokines, the systemic cellular response to soluble Toxoplasma antigen does not differ between patients with either ocular or asymptomatic toxoplasmosis (Fatoohi et al. 2006).

Indirect evidence for a protective role of IFN- $\gamma$ in OT has been obtained using a synthetic polymeric complex of polyinosinic and polycytidylic acids, which is a potent inducer of IFN. The prophylactic application of this polymer delays the development of lesions in the retina of Toxoplasma-infected eyes, but it does not completely suppress the disease (Oh \& O'Connor 1971). In a more recent study carried out with mice, IFN- $\gamma$ was reported to regulate the ocular load and distribution of T. gondii (Norose et al. 2003). In humans, higher levels of IFN- $\gamma$ and 10 -fold higher numerical densities of activated CD25(+) T-cells have been reported in blood cultures derived from Toxoplasma-infected patients than in those from healthy controls after stimulation with soluble Toxoplasma antigen. No differences were observed between patients with either ocular or asymptomatic toxoplasmosis. Chronic infection with Toxoplasma thus appears to be associated with a sustained stimulation of IFN- $\gamma$ production. This variable might impact the recurrence behaviour (Fatoohi et al. 2006). Mutant mice that lack CD25(+) and CD4(+) T(reg)-cells spontaneously develop autoimmune uveoretinitis (Takeuchi et al. 2004). Hence, the marked activation of CD25(+) T(reg)-cells that is associated with OT in wild-type mice could protect the host against autoimmunity in this disease. The numerical densities of CD4(+) and CD25(+) T(reg)-cells are increased in the eyes of mice with experimental autoimmune uveitis during the resolution of the first attack. During reactivation of the disease, the response is weaker and corresponds with lower levels of IL-10 in the aqueous humour (Ke et al. 2008).

Experimentally, IL-10 has been shown to be important in the regulation of inflammation during acute OT ( $\mathrm{Lu}$ et al. 2003). Although several immunoregulatory cytokines (IL-6, IL-10, and IFN- $\gamma$ ) have been detected in samples of human ocular fluid, a clear role for either a $\mathrm{T}(\mathrm{H})-1$ or a $\mathrm{T}(\mathrm{H})$-2-cell mediated response in the pathogenesis of clinical uveitis has yet to be determined (Ongkosuwito et al. 1998). In mice that are chronically infected with Toxoplasma, the intraocular RNA levels for TGF $\beta$, TNF- $\alpha$ and IL- 6 are elevated, whereas those for IL-1- $\alpha$ are depressed. IL-6 is believed to play a role in controlling parasitic growth and inflammation (Lyons et al. 2001).

Human retinal pigmented epithelial cells respond to infection with $T$. gondii in vitro by secreting IL-1 $\beta$ (23fold increase), IL-6 (10-fold increase), granulocyte macrophage colony-stimulating factor (8-fold increase) and intercellular adhesion molecule 1 (5-fold increase). These molecules may play a critical immunoregulatory role in the pathophysiological processes that are associated with OT (Nagineni et al. 1996, 2000). TGF- $\beta$, on the other hand, promotes replication of T. gondii (Nagineni et al. 2002).

In a murine model of OT, focal ocular inflammation, with involvement of the retinal pigmented epithelium, was observed two weeks after inoculation with an avirulent strain of $T$. gondii. By the fourth week, the ocular inflammatory response had abated and ocular cysts were rarely observed. In many of the retinal lesions, no parasitic DNA could be detected. These findings indicate that the formation of retinal lesions was instigated by the inflammatory response to the infection, not by the parasite itself. Treatment of the mice with a monoclonal antibody against CD4(+)- and CD8(+) T-cells, IFN- $\gamma$ or TNF- $\alpha$ led to a marked increase in the number of retinal lesions. These lesions were often associated with the presence of parasites, as well as with a severe inflammatory response (Gazzinelli et al. 1994).

In human OT, the levels of IL-6 are markedly raised in the aqueous humour, but not in the serum (Murray et al. 1990). In patients with acute retinal necrosis, the ocular levels of IL-6 have been reported to be 5-fold higher than in those with OT. In the latter, the ocular levels of IFN- $\gamma$ and IL-10 were raised in about $50 \%$ of the cases; IL-2 was rarely detected in either patient category. A distinct role for either $\mathrm{T}(\mathrm{H})-1$ or $\mathrm{T}(\mathrm{H})-2$ cells in the pathogenesis of either OT or acute retinal necrosis could not be demonstrated (Ongkosuwito et al. 1998).

\section{CONCLUSIONS}

In clinically manifested cases of retinal vasculitis and vitritis, which are the hallmarks of active OT, an imbalance in the IL-17/IL-27 axis appears to be a prerequisite for inflammatory and tissue-hypersensitivity responses. This imbalance tends to be more pronounced in patients who have been infected with Toxoplasma postnatally than in those with congenital infection. T(reg)cells may thus play a crucial role in ocular inflammation and their dysregulation or malfunction could contribute to the severity of OT and to its recurrence. These factors could partially account for the long-suspected, but still unconfirmed, autoimmune characteristics of recurrent OT. Similar immunoregulatory phenomena have been reported in the inflammatory states associated with organ transplantation and overt autoimmune diseases (Afzali et al. 2007). 


\section{REFERENCES}

Afzali B, Lombardi G, Lechler RI, Lord GM 2007. The role of T helper $17(\mathrm{~T}(\mathrm{H})-17)$ and regulatory T cells (Treg) in human organ transplantation and autoimmune disease. Clin Exp Immunol 148: 32-46.

Amadi-Obi A, Yu CR, Liu X, Mahdi RM, Clarke GL, Nussenblatt RB, Gery I, Lee YS, Egwuagu CE 2007. T(H)-17 cells contribute to uveitis and scleritis and are expanded by IL-2 and inhibited by IL-27/STAT1. Nat Med 13: 711-718.

Awasthi A, Carrier Y, Peron JP, Bettelli E, Kamanaka M, Flavell RA, Kuchroo VK, Oukka M, Weiner HL 2007. A dominant function for interleukin 27 in generating interleukin 10-producing antiinflammatory T cells. Nat Immunol 8: 1380-1389.

Batten M, Li J, Yi S, Kljavin NM, Danilenko DM, Lucas S, Lee J, de Sauvage FJ, Ghilardi N 2006. Interleukin 27 limits autoimmune encephalomyelitis by suppressing the development of interleukin 17-producing T cells. Nat Immunol 7: 929-936.

Benedetto N, Folgore A, Romano Carratelli C, Galdiero F 2001. Effects of cytokines and prolactin on the replication of Toxoplasma gondii in murine microglia. Eur Cytokine Netw 12: 348-358.

Bettelli E, Carrier Y, Gao W, Korn T, Strom TB, Oukka M, Weiner HL, Kuchroo VK 2006. Reciprocal developmental pathways for the generation of pathogenic effector $\mathrm{T}(\mathrm{H})-17$ and regulatory $\mathrm{T}$ cells. Nature 441: 235-238.

Bettelli E, Oukka M, Kuchroo VK 2007 T(H)-17 cells in the circle of immunity and autoimmunity. Nat Immunol 8: 345-350.

Calabrese KS, Tedesco RC, Zaverucha do Valle T, Barbosa HS 2008. Serum and aqueous humour cytokine response and histopathological alterations during ocular Toxoplasma gondii infection in C57BL/6 mice. Micron 39: 1335-1341.

Caspi RR 2006. Ocular immunity: price of privilege. Immunol Res 213: 23-35.

Chen Y, Langrish CL, McKenzie B, Joyce-Shaikh B, Stumhofer JS, McClanahan T, Blumenschein W, Churakovsa T, Low J, Presta L, Hunter CA, Kastelein RA, Cua DJ 2006. Anti-IL-23 therapy inhibits multiple inflammatory pathways and ameliorates autoimmune encephalomyelitis. J Clin Invest 116: 1317-1326.

Cogan DG 1977. Immunosuppression and eye disease. First vail lecture. Am J Ophthalmol 83: 777-788.

Cordeiro CA, Moreira PR, Andrade MS, Dutra WO, Campos WR, Oréfice F, Teixeira AL 2008. Interleukin-10 gene polymorphism $(-1082 \mathrm{G} / \mathrm{A})$ is associated with toxoplasmic retinochoroiditis. Invest Ophthalmol Vis Sci 49: 1979-1982.

Cordoba-Rodriguez R, Frucht DM 2003. IL-23 and IL-27: new members of the growing family of IL-12-related cytokines with important implications for therapeutics. Expert Opin Biol Ther 3: 715-723.

Deckert M, Lütjen S, Leuker CE, Kwok LY, Strack A, Müller W, Wagner N, Schlüter D 2003. Mice with neonatally induced inactivation of the vascular cell adhesion molecule-1 fail to control the parasite in Toxoplasma encephalitis. Eur J Immunol 33: 1418-1428.

Deckert-Schlüter M, Buck C, Weiner D, Kaefer N, Rang A, Hof H, Wiestler OD, Schlüter D 1997. Interleukin-10 downregulates the intracerebral immune response in chronic Toxoplasma encephalitis. J Neuroimmunol 76: 167-176.

Dong C 2006. Diversification of T-helper-cell lineages: finding the family root of IL-17-producing (T(H)-17) cells. Nat Rev Immunol 6: 329-333.

Esterre P 1996. Immune reactions in the brain. Arch Inst Pasteur Madagascar 63: 24-30.
Fatoohi F, Cozon GJ, Wallon M, Kodjikian L, Peyron F 2006. Systemic $\mathrm{T}$ cell response to Toxoplasma gondii antigen in patients with ocular toxoplasmosis. Jpn J Ophthalmol 50: 103-110.

Feron EJ, Klaren VN, Wierenga EA, Verjans GM, Kijlstra A 2001. Characterization of Toxoplasma gondii-specific T cells recovered from vitreous fluid of patients with ocular toxoplasmosis. Invest Ophthalmol Vis Sci 42: 3228-3232.

Fitzgerald DC, Ciric B, Touil T, Harle H, Grammatikopolou J, Das Sarma J, Gran B, Zhang GX, Rostami A 2007. Suppressive effect of IL-27 on encephalitogenic T(H)-17 cells and the effector phase of experimental autoimmune encephalomyelitis. J Immunol 179: 3268-3275.

Forrester JV, Stott DI, Hercus KM 1989. Naturally occurring antibodies to bovine and human retinal $\mathrm{S}$ antigen: a comparison between uveitis patients and healthy volunteers. Br J Ophthalmol 73: 155-159.

Furuzawa-Carballeda J, Vargas-Rojas MI, Cabral AR 2007. Autoimmune inflammation from the $\mathrm{T}(\mathrm{H})-17$ perspective. Autoimmun Rev 6: 169-175.

Gaddi PJ, Yap GS 2007. Cytokine regulation of immunopathology in toxoplasmosis. Immunol Cell Biol 85: 155-159.

García H, Dante C, Calderon G, Antonio P 1988. Production of specific retinal $\mathrm{S}$ antigen antibodies in patients with retinal detachment. Graefes Arch Clin Exp Ophthalmol 226: 428-430.

Gazzinelli RT, Brézin A, Li Q, Nussenblatt RB, Chan CC 1994. Toxoplasma gondii: acquired ocular toxoplasmosis in the murine model, protective role of TNF-alpha and IFN-gamma. Exp Parasitol 78: $217-229$.

Gocke AR, Cravens PD, Ben LH, Hussain RZ, Northrop SC, Racke MK, Lovett-Racke AE 2007. T-bet regulates the fate of T(H)-1 and $\mathrm{T}(\mathrm{H})-17$ lymphocytes in autoimmunity. J Immunol 178: 1341-1348.

Gonçalves RM, Rodrigues DH, Camargos da Costa AM, Teixeira MM, Ribeiro Campos W, Oréfice F, Teixeira AL 2007. Increased serum levels of CXCL8 chemokine in acute toxoplasmic retinochoroiditis. Acta Ophthalmol Scand 85: 871-876.

Harrington LE, Hatton RD, Mangan PR, Turner H, Murphy TL, Murphy KM, Weaver CT 2005. Interleukin 17-producing CD4(+) effector $\mathrm{T}$ cells develop via a lineage distinct from the Thelper type 1 and 2 lineages. Nat Immunol 6: 1123-1132.

Hay J, Hutchison WM, Lee WR, Siim JC 1981. Cataract in mice congenitally infected with Toxoplasma gondii. Ann Trop Med Parasitol 75: 455-457.

Hay J, Lee WR, Dutton GN, Hutchison WM, Siim JC 1984. Congenital toxoplasmic retinochoroiditis in a mouse model. Ann Trop Med Parasitol 78: 109-116.

Hoekzema R, Hwan SB, Rothova A, van Haren MA, Donoso LA, Kijlstra A 1990. Serum antibody response to human and bovine IRBP in uveitis. Curr Eye Res 9: 1177-1183.

Hu MS, Schwartzman JD, Yeaman GR, Collins J, Seguin R, Khan IA, Kasper LH 1999. Fas-FasL interaction involved in pathogenesis of ocular toxoplasmosis in mice. Infect Immun 67: 928-935.

Hunter CA 2005. New IL-12-family members: IL-23 and IL-27, cytokines with divergent functions. Nat Rev Immunol 5: 521-531.

Hutchison WM, Hay J, Lee WR, Siim JC 1982. A study of cataract in murine congenital toxoplasmosis. Ann Trop Med Parasitol 76: $53-70$.

Ifergan I, Kébir H, Bernard M, Wosik K, Dodelet-Devillers A, Cayrol R, Arbour N, Prat A 2008. The blood-brain barrier induces differentiation of migrating monocytes into $\mathrm{T}(\mathrm{H})$-17-polarizing dendritic cells. Brain 131: 785-799. 
Iwakura Y, Ishigame H 2006. The IL-23/IL-17 axis in inflammation. J Clin Invest 116: 1218-1222.

Jankovic D, Kullberg MC, Feng CG, Goldszmid RS, Collazo CM, Wilson M, Wynn TA, Kamanaka M, Flavell RA, Sher A 2007. Conventional T-bet(+)Foxp3(-) T(H)-1 cells are the major source of host-protective regulatory IL-10 during intracellular protozoan infection. J Exp Med 204: 273-283.

Ke Y, Jiang G, Sun D, Kaplan HJ, Shao H 2008. Ocular regulatory $\mathrm{T}$ cells distinguish monophasic from recurrent autoimmune uveitis. Invest Ophthalmol Vis Sci 49: 3999-4007.

Kebir H, Kreymborg K, Ifergan I, Dodelet-Devillers A, Cayrol R, Bernard M, Giuliani F, Arbour N, Becher B, Prat A 2007. Human $\mathrm{T}(\mathrm{H})-17$ lymphocytes promote blood-brain barrier disruption and central nervous system inflammation. Nat Med 13: 1173-1175.

Kelly MN, Kolls JK, Happel K, Schwartzman JD, Schwarzenberger P, Combe C, Moretto M, Khan IA 2005. Interleukin-17/interleukin-17 receptor-mediated signaling is important for generation of an optimal polymorphonuclear response against Toxoplasma gondii infection. Infect Immun 73: 617-621.

Kijlstra A, Hoekzema R, vd Lelij A, Doekes G, Rothova A 1990. Humoral and cellular immune reactions against retinal antigens in clinical disease. Curr Eye Res 9 (Suppl.): 85-89.

Klaren VN, Peek R 2001. Evidence for a compartmentalized B cell response as characterized by $\operatorname{IgG}$ epitope specificity in human ocular toxoplasmosis. J Immunol 167: 6263-6269.

Klass M, Böhnke M, Damms T, Knospe V 1991. Humoral immune response to retinal S-antigen in patients with uveitis. Fortschr Ophthalmol 88: 450-454.

Knight BC, Brunton CL, Modi NC, Wallace GR, Stanford MR 2005. The effect of Toxoplasma gondii infection on expression of chemokines by rat retinal vascular endothelial cells. $J$ Neuroimmunol 160: 41-47.

Knight BC, Kissane S, Falciani F, Salmon M, Stanford MR, Wallace GR 2006. Expression analysis of immune response genes of Müller cells infected with Toxoplasma gondii. J Neuroimmunol 179: 126-131.

Kryczek I, Wei S, Vatan L, Escara-Wilke J, Szeliga W, Keller ET, Zou W 2007. Cutting edge: opposite effects of IL-1 and IL-2 on the regulation of IL-17+ T cell pool IL-1 subverts IL-2-mediated suppression. J Immunol 179: 1423-1426.

Lee HO, Herndon JM, Barreiro R, Griffith TS, Ferguson TA 2002. TRAIL: a mechanism of tumor surveillance in an immune privileged site. J Immunol 169: 4739-4744.

Lee WR, Hay J, Hutchison WM, Dutton GN, Siim JC 1983. A murine model of congenital toxoplasmic retinochoroiditis. Acta Ophthalmol (Copenh) 61: 818-830.

Lu F, Huang S, Hu MS, Kasper LH 2005. Experimental ocular toxoplasmosis in genetically susceptible and resistant mice. Infect Immun 73: 5160-5165.

Lu F, Huang S, Kasper LH 2003. Interleukin-10 and pathogenesis of murine ocular toxoplasmosis. Infect Immun 71: 7159-7163.

Lu F, Huang S, Kasper LH 2004. CD4(+) T cells in the pathogenesis of murine ocular toxoplasmosis. Infect Immun 72: 4966-4972.

Luger D, Caspi RR 2008. New perspectives on effector mechanism in uveitis. Semin Immunopathol 30: 135-143.

Lyons RE, Anthony JP, Ferguson DJ, Byrne N, Alexander J, Roberts F, Roberts CW 2001. Immunological studies of chronic ocular toxoplasmosis: up-regulation of major histocompatibility complex class I and transforming growth factor beta and a protective role for interleukin-6. Infect Immun 69: 2589-2595.
Matsumura Y, Kobayashi T, Ichiyama K, Yoshida R, Hashimoto M, Takimoto T, Tanaka K, Chinen T, Shichita T, Wyss-Coray T, Sato K, Yoshimura A 2007. Selective expansion of foxp3-positive regulatory $\mathrm{T}$ cells and immunosuppression by suppressors of cytokine signaling 3-deficient dendritic cells. J Immunol 179: 2170-2179.

McKenzie BS, Kastelein RA, Cua DJ 2006. Understanding the IL-23IL-17 immune pathway. Trends Immunol 27: 17-23.

Miller R, Wen X, Dunford B, Wang X, Suzuki Y 2006. Cytokine production of $\mathrm{CD} 8+$ immune $\mathrm{T}$ cells but not of CD4(+) T cells from Toxoplasma gondii-infected mice is polarized to a type 1 response following stimulation with tachyzoite-infected macrophages. J Interferon Cytokine Res 26: 787-792.

Mordue DG, Monroy F, La Regina M, Dinarello CA, Sibley LD 2001. Acute toxoplasmosis leads to lethal overproduction of T(H)-1 cytokines. J Immunol 167: 4574-4584.

Mucida D, Park Y, Kim G, Turovskaya O, Scott I, Kronenberg M, Cheroutre H 2007. Reciprocal $\mathrm{T}(\mathrm{H})-17$ and regulatory $\mathrm{T}$ cell differentiation mediated by retinoic acid. Science 317: 256-260.

Muiño JC, Juárez CP, Luna JD, Castro CC, Wolff EG, Ferrero M, Romero-Piffiguer MD 1999. The importance of specific IgG and $\operatorname{IgE}$ autoantibodies to retinal $\mathrm{S}$ antigen, total serum $\operatorname{IgE}$, and sCD23 levels in autoimmune and infectious uveitis. J Clin Immunol 19: 215-222.

Murray PI, Hoekzema R, van Haren MA, de Hon FD, Kijlstra A 1990. Aqueous humor interleukin-6 levels in uveitis. Invest Ophthalmol Vis Sci 31: 917-920.

Nagineni CN, Detrick B, Hooks JJ 2000. Toxoplasma gondii infection induces gene expression and secretion of interleukin 1 (IL-1), IL6 , granulocyte-macrophage colony-stimulating factor, and intercellular adhesion molecule 1 by human retinal pigment epithelial cells. Infect Immun 68: 407-410

Nagineni CN, Detrick B, Hooks JJ 2002. Transforming growth factorbeta expression in human retinal pigment epithelial cells is enhanced by Toxoplasma gondii: a possible role in the immunopathogenesis of retinochoroiditis. Clin Exp Immunol 128: 372-378.

Nagineni CN, Pardhasaradhi K, Martins MC, Detrick B, Hooks JJ 1996. Mechanisms of interferon-induced inhibition of Toxoplasma gondii replication in human retinal pigment epithelial cells. Infect Immun 64: 4188-4196.

Neufert C, Becker C, Wirtz S, Fantini MC, Weigmann B, Galle PR, Neurath MF 2007. IL-27 controls the development of inducible regulatory $\mathrm{T}$ cells and $\mathrm{T}(\mathrm{H})-17$ cells via differential effects on STAT1. Eur J Immunol 37: 1809-1816.

Norose K, Mun HS, Aosai F, Chen M, Piao LX, Kobayashi M, Iwakura Y, Yano A 2003. IFN-gamma-regulated Toxoplasma gondii distribution and load in the murine eye. Invest Ophthalmol Vis Sci 44: 4375-4381.

Nussenblatt RB, Mittal KK, Fuhrman S, Sharma SD, Palestine AG 1989. Lymphocyte proliferative responses of patients with ocular toxoplasmosis to parasite and retinal antigens. Am J Ophthalmol 107: 632-641.

O'Connor GR. Factors related to the initiation and recurrence of uveitis 1983. XL Edward Jackson memorial lecture. Am J Ophthalmol 96: $577-599$.

Oh JO, O'Connor GR 1971. Effects of an interferon inducer, poly I:C, on acute ocular infection produced by intracameral inoculation of Toxoplasma gondii. Infect Immun 4: 407-410.

Ohno S, O'Connor GR, Kimura SJ 1977. HLA antigens and toxoplasmic retinochoroiditis. Tohoku J Exp Med 123: 91-94. 
Ongkosuwito JV, Feron EJ, van Doornik CE, Van der Lelij A, Hoyng CB, La Heij EC, Kijlstra A 1998. Analysis of immunoregulatory cytokines in ocular fluid samples from patients with uveitis. Invest Ophthalmol Vis Sci 39: 2659-2665.

Park H, Li Z, Yang XO, Chang SH, Nurieva R, Wang YH, Wang Y, Hood L, Zhu Z, Tian Q, Dong C 2005. A distinct lineage of CD4 $\mathrm{T}$ cells regulates tissue inflammation by producing interleukin 17. Nat Immunol 6: 1133-1141.

Pereira Mde F, Silva DA, Ferro EA, Mineo JR 1999. Acquired and congenital ocular toxoplasmosis experimentally induced in Calomys callosus (Rodentia, Cricetidae). Mem Inst Oswaldo Cruz 94: 103-114.

Rahi AH, Addison DJ 1983. Autoimmunity and the outer retina. Trans Ophthalmol Soc UK 103: 428-437.

Roberts F, McLeod R 1999. Pathogenesis of toxoplasmic retinochoroiditis. Parasitol Today 15: 51-57.

Romagnani S 2008. Human T(H)-17 cells. Arthritis Res Ther 10: 206.

Sergent V, Cautain B, Khalife J, Deslée D, Bastien P, Dao A, Dubremetz JF, Fournié GJ, Saoudi A, Cesbron-Delauw MF 2005. Innate refractoriness of the Lewis rat to toxoplasmosis is a dominant trait that is intrinsic to bone marrow-derived cells. Infect Immun 73: 6990-6997.

Shen DF, Matteson DM, Tuaillon N, Suedekum BK, Buggage RR, Chan CC 2001. Involvement of apoptosis and interferon-gamma in murine toxoplasmosis. Invest Ophthalmol Vis Sci 42: 2031-2036.

Stumhofer JS, Laurence A, Wilson EH, Huang E, Tato CM, Johnson LM, Villarino AV, Huang Q, Yoshimura A, Sehy D, Saris CJ, O'Shea JJ, Hennighausen L, Ernst M, Hunter CA 2006. Interleukin 27 negatively regulates the development of interleukin 17 -producing $\mathrm{T}$ helper cells during chronic inflammation of the central nervous system. Nat Immunol 7: 937-945.

Stumhofer JS, Silver JS, Laurence A, Porrett PM, Harris TH, Turka LA, Ernst M, Saris CJ, O'Shea JJ, Hunter CA 2007. Interleukins 27 and 6 induce STAT3-mediated T cell production of interleukin 10. Nat Immunol 8: 1363-1371.

Sugita S, Taguchi C, Takase H, Sagawa K, Sueda J, Fukushi K, Hikita N, Watanabe T, Itoh K, Mochizuki M 2000. Soluble Fas ligand and soluble Fas in ocular fluid of patients with uveitis. Br J Ophthalmol 84: 1130-1134.
Takeuchi M, Keino H, Kezuka T, Usui M, Taguchi O 2004. Immune responses to retinal self-antigens in $\mathrm{CD} 25(+) \mathrm{CD} 4(+)$ regulatory T-cell-depleted mice. Invest Ophthalmol Vis Sci 45: 1879-1886.

Vallochi AL, da Silva Rios L, Nakamura MV, Silveira C, Muccioli C, Martins MC, Belfort R Jr, Rizzo LV 2005. The involvement of autoimmunity against retinal antigens in determining disease severity in toxoplasmosis. J Autoimmun 24: 25-32.

Villarino AV, Stumhofer JS, Saris CJ, Kastelein RA, de Sauvage FJ, Hunter CA 2006. IL-27 limits IL-2 production during T(H)-1 differentiation. J Immunol 176: 237-247.

Wang J, Wang G, Sun B, Li H, Mu L, Wang Q, Li G, Shi L, Jin L, Kostulas N 2008. Interleukin-27 suppresses experimental autoimmune encephalomyelitis during bone marrow stromal cell treatment. J Autoimmun 30: 222-229.

Wang X, Suzuki Y 2007. Microglia produce IFN-gamma independently from $\mathrm{T}$ cells during acute toxoplasmosis in the brain. $J$ Interferon Cytokine Res 27: 599-605.

Welter A, Mineo JR, de Oliveira Silva DA, Lourenço EV, Vieira Ferro EA, Roque-Barreira MC, Maria da Silva N 2007. BALB/c mice resistant to Toxoplasma gondii infection proved to be highly susceptible when previously infected with Myocoptes musculinus fur mites. Int $J$ Exp Pathol 88: 325-335.

Whittle RM, Wallace GR, Whiston RA, Dumonde DC, Stanford MR 1998. Human antiretinal antibodies in toxoplasma retinochoroiditis. Br J Ophthalmol 82: 1017-1021.

Wyler DJ, Blackman HJ, Lunde MN 1980. Cellular hypersensitivity to toxoplasmal and retinal antigens in patients with toxoplasma retinochoroiditis. Am J Trop Med Hyg 29: 1181-1186.

Yagi J, Arimura Y, Takatori H, Nakajima H, Iwamoto I, Uchiyama $\mathrm{T}$ 2006. Genetic background influences Th cell differentiation by controlling the capacity for IL-2-induced IL-4 production by naïve CD4(+) T cells. Int Immunol 18: 1681-1690.

Yap GS, Sher A 1999. Cell-mediated immunity to Toxoplasma gondii: initiation, regulation and effector function. Immunobiology 201: 240-247.

Zhang H, Yang P, Zhou H, Meng Q, Huang X 2008. Involvement of Foxp3-expressing CD4(+) CD25+ regulatory T cells in the development of tolerance induced by transforming growth factor-beta2-treated antigen-presenting cells. Immunology 124: 304-314. 